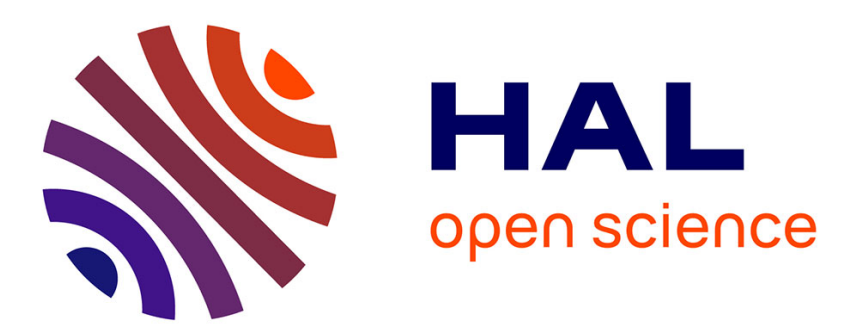

\title{
Assessment of lipid peroxidation and artificial neural network models in early Alzheimer Disease diagnosis
}

Carmen Peña-Bautista, Thierry Durand, Camille Oger, Miguel Baquero, Máximo Vento, Consuelo Cháfer-Pericás

\section{- To cite this version:}

Carmen Peña-Bautista, Thierry Durand, Camille Oger, Miguel Baquero, Máximo Vento, et al.. Assessment of lipid peroxidation and artificial neural network models in early Alzheimer Disease diagnosis. Clinical Biochemistry, 2019, 10.1016/j.clinbiochem.2019.07.008 . hal-02394946

\author{
HAL Id: hal-02394946 \\ https://hal.science/hal-02394946
}

Submitted on 5 Dec 2019

HAL is a multi-disciplinary open access archive for the deposit and dissemination of scientific research documents, whether they are published or not. The documents may come from teaching and research institutions in France or abroad, or from public or private research centers.
L'archive ouverte pluridisciplinaire HAL, est destinée au dépôt et à la diffusion de documents scientifiques de niveau recherche, publiés ou non, émanant des établissements d'enseignement et de recherche français ou étrangers, des laboratoires publics ou privés. 


\title{
Assessment of lipid peroxidation and artificial neural network models in early Alzheimer Disease diagnosis
}

\author{
Carmen Peña-Bautista ${ }^{\mathrm{a}}$, Thierry Durand ${ }^{\mathrm{b}}$, Camille Oger $^{\mathrm{b}}$, Miguel Baquero ${ }^{\mathrm{c}}$, Máximo Vento ${ }^{\mathrm{a}}$, \\ Consuelo Cháfer-Pericás ${ }^{\mathrm{a}, *}$ \\ ${ }^{a}$ Neonatal Research Unit, Health Research Institute La Fe, Valencia, Spain \\ ${ }^{\mathrm{b}}$ Institut des Biomolécules Max Mousseron, IBMM, University of Montpellier, CNRS ENSCM, Montpellier, France \\ ${ }^{\mathrm{c}}$ Neurology Unit, University and Polytechnic Hospital La Fe, Valencia, Spain
}

\section{A R T I C L E I N F O}

\section{Keywords:}

Alzheimer Disease

Artificial neural network

Mass spectrometry

Partial least squares

Plasma

Lipid peroxidation

Urine

\begin{abstract}
A B S T R A C T
Objective: Lipid peroxidation constitutes a molecular mechanism involved in early Alzheimer Disease (AD) stages, and artificial neural network (ANN) analysis is a promising non-linear regression model, characterized by its high flexibility and utility in clinical diagnosis. ANN simulates neuron learning procedures and it could provide good diagnostic performances in this complex and heterogeneous disease compared with linear regression analysis. Design and Methods: In our study, a new set of lipid peroxidation compounds were determined in urine and plasma samples from patients diagnosed with early Alzheimer Disease $(n=70)$ and healthy controls ( $n=26$ ) by means of ultra-performance liquid chromatography coupled with tandem mass-spectrometry. Then, a model based on ANN was developed to classify groups of participants. Results: The diagnostic performances obtained using an ANN model for each biological matrix were compared with the corresponding linear regression model based on partial least squares (PLS), and with the non-linear (radial and polynomial) support vector machine (SVM) models. Better accuracy, in terms of receiver operating characteristic-area under curve (ROC-AUC), was obtained for the ANN models (ROC-AUC 0.882 in plasma and 0.839 in urine) than for PLS and SVM models. Conclusion: Lipid peroxidation and ANN constitute a useful approach to establish a reliable diagnosis when the prognosis is complex, multidimensional and non-linear.
\end{abstract}

\section{Introduction}

Alzheimer disease (AD) early diagnosis constitutes a subject of great concern, since $\mathrm{AD}$ is the main cause of dementia in the world, and it causes great burden on patients and families/care providers, as well as high social and economic impact [1]. In addition, there is a lack of effective therapeutic targets as well as non-invasive and cost-effective molecular diagnostic models, probably due to incomplete understanding of the $\mathrm{AD}$ pathophysiological mechanisms.

Nowadays, both the onset and development of $\mathrm{AD}$ have been linked to lipid peroxidation mechanisms given the high lipid composition, high metabolic activity and high oxygen consumption of the brain [2-4]. In fact, previous studies based on lipid peroxidation improved the understanding of pathophysiological mechanisms underlying $\mathrm{AD}$, and also established new biomarkers for diagnosis, prognosis and therapeutic purposes [5]. Specifically, different isoprostanoids have been determined in cerebrospinal fluid samples (CSF) [6,7], plasma and serum [8], and in urine samples [9,10], showing correlation with early
AD. These compounds can be classified depending on the modified lipid from which they derived. Thus, isoprostanes/isofurans are produced from arachidonic acid oxidation (all tissues), neuroprostanes/neurofurans from docosahexanoic acid oxidation (brain grey matter), and dihomo-isoprostanes/di-homo-isofurans from adrenic acid oxidation (brain white matter) [11]. In this sense, although some potential biomarkers have been identified, they have not been clinically validated $[12,13]$. In addition, some predictive models, mainly based on linear regression, have been developed [14,15], but the complexity of $\mathrm{AD}$ physiopathology could demand non-linear regression models to obtain satisfactory diagnostic results.

Artificial neural network (ANN) constitutes a promising statistical tool since it is flexible and can model highly non-linear systems, in which the relationships between variables are unknown or very complex [16-18]. The ANN models simulate the learning process carried out by the neurons, establishing connections among different variables, and allowing a complex data analysis through mathematical functions [17]. Neurons are placed in several layers (input, hidden, output) in the

\footnotetext{
* Corresponding author at: Health Research Institute La Fe, Avda de Fernando Abril Martorell, 106, 46026, Valencia, Spain

E-mail address: m.consuelo.chafer@uv.es (C. Cháfer-Pericás).
} 
ANN. Specifically, the predictor variables are in the input layer, and the response variables are in the output layer. Then, some connections, similar to those in synapses, are established among the variables by means of different mathematical functions (hyperbolic, sigmoid...), and different coefficients are assigned to these interactions in order to improve the model's classification ability [19]. In this sense, ANN analysis is based on supervised learning which has the advantage of being tolerant with the highly complex and noisy data obtained from biological samples [17]. ANN analysis has also some disadvantages, namely the inability to exactly reproduce the same model due to the complex learning processes involved in the models' development [16], as well as the fact of being considered a "black box" by some authors [17].

Nowadays, there is an increasing body of research applying ANN analysis to clinical diagnosis, since it allows to establish complex interactions among variables involved in some multifactorial pathologies [20]. In fact, recent studies have provided satisfactory diagnostic results in different clinical areas [21-25]. However, few studies have compared the clinical predictive capacity of ANN models with linear regression models, and better results, in terms of accuracy, seem to be obtained from ANN analysis [26,27]. Among ANN studies focusing on early $\mathrm{AD}$ diagnosis, most of them were based on neurophysiological signals (electroencephalogram, neurofibrillary tangles) [28] or image tests [29-32], requiring high cost and highly specialized staff to interpret the results. Other ANN models based on neuropsychological tests and clinical variables predicted brain AD characteristic lesions (amyloid plaques, neurofibrillary tangles) [33], as well as mild cognitive impairment in elderly individuals [25,26]. Nevertheless, some neuropsychological tests are influenced by the patients' educational level, since high educational level could mask cognitive alteration and very low educational level (illiteracy) prevents the neuropsychological evaluation. An ANN model based on Raman spectroscopy in serum was employed to discriminate among $\mathrm{AD}$ patients, healthy individuals, and other types of dementias; however, this expensive equipment is not available in the clinical practice [34]. Moreover, some ANN models have also been developed using different biomarkers in blood, such as glucose and apolipoprotein E genotype as AD risk factors [35,36]. To our knowledge, ANN analysis has not ever been assessed as an early AD detection model from lipid peroxidation compounds, which are determined by validated analytical methods in plasma or urine samples.

The aim of this study was to develop and evaluate ANN models, in terms of complex disease diagnostic performance, comparing them with other linear and non-linear models. For this, a new set of lipid peroxidation biomarkers was determined in urine and plasma samples from well-defined mild cognitive-impairment due to AD patients and healthy participants.

\section{Materials and methods}

\subsection{Patients and samples}

Urine and plasma samples were collected from participants recruited in the University and Polytechnic Hospital La Fe (Valencia, Spain). They were classified as mild cognitive impairment due to Alzheimer's disease (MCI-AD, $n=70$ ) and healthy control participants ( $n=26$ ) based on neuropsychological tests, structural neuroimaging, and CSF biomarkers ( $\beta$-amyloid, total Tau, phosphorylated Tau) [37]. The study protocol was approved by the Ethics Committee (CEIC) of the Health Research Institute La Fe (Valencia, Spain), and informed consent was obtained from all the participants.

\subsection{Analytical method}

The samples were processed as indicated in previous studies, where the corresponding sample treatment procedures were optimized $[9,38]$. Thereafter, the samples were injected into the chromatographic system (UPLC-MS/MS) following previously validated analytical methods whose chromatographic and detection conditions were described in previous works $[9,38]$. Finally, the levels of a new set of lipid peroxidation biomarkers (isoprostanes, neuroprostanes, dihomoisoprostanes, isofurans, neurofurans, dihomoisofurans) were obtained.

\subsection{Statistical analysis}

Different regression models, based on linear discriminant analysis (partial least squares, PLS) and non-linear discriminant analysis (support vector machine, SVM; artificial neural networks, ANN), have been developed from lipid peroxidation compounds levels determined in urine and plasma samples from healthy and MCI-AD participants. Each model was trained and tested multiple times, and the diagnostic performance obtained for each model was evaluated.

The PLS analysis was carried out with the Unscrambler software version 7.6 (Camo, Woodbridge, USA), the SVM analysis with radial and polynomial kernel functions was carried out with IBM SPSS Modeler software version 1.0 (IBM, New York, USA) and the ANN analysis was carried out with SPSS software version 20.0 (SPSS, Inc., Chicago, IL, USA). These statistical multivariate models were developed for each sample matrix that was analyzed.

The PLS models were constructed from 24 independent variables (22 lipid peroxidation compounds, gender and age) as predictor variables, 1 dependent variable (participant group (MCI-AD/healthy control)) and 5 principal components. All variables were normalized, and a random cross validation (one left out) was carried out.

The SVM models with radial and polynomial kernel functions were developed from 24 independent variables (22 lipid peroxidation analytes, gender and age) and 1 dependent variable (participant group (MCI-AD/healthy control)). The dataset was randomly divided into training sample $(70 \%)$, testing sample $(15 \%)$ and validating sample (15\%). The parameters utilized were detention criteria of $1.0 \mathrm{E}^{-3}$, regularization parameter $(C)$ of 10 , precision of regression of 0.1 , and the kernel functions employed were radial basis function (gamma $(\gamma)$ of 0.1 ) and polynomial function ( $\gamma$ of 1 ).

The ANN models were constructed from the 24 independent variables (gender and age as factors, 22 analytes as covariables), and 1 dependent variable (participant group (MCI-AD/healthy control)). In the first step, the dataset was randomly divided into training sample (70\%), testing sample (15\%) and validating sample (15\%) [18], before model development. The training sample is used to train the network in several iterations improving the ANN performance. Then, the optimum values of weights and biases are determined, and the ANN performance is examined in the testing sample. The feedforward architecture was based on the predictors function Multilayer Perceptron (MPL), as training algorithm, that minimizes the prediction error of outputs, and the form of this function consists of input, hidden and output layers, but the number of neurons in each layer as well as the number of layers depend on the complexity of the studied system. The automatic architecture selection builds a network with one hidden layer, and the number of units in the hidden layer was tested between 1 and 50, 1 unit being the optimum number. The transfer functions for the hidden and output layers were hyperbolic tangent and normalized exponential function, respectively. These functions have the following forms:

$\gamma(\mathrm{x})=\tanh (\mathrm{x})=\left(\mathrm{e}^{\mathrm{x}}-\mathrm{e}^{-\mathrm{x}}\right) /\left(\mathrm{e}^{\mathrm{x}}+\mathrm{e}^{-\mathrm{x}}\right)$

$\gamma\left(\mathrm{x}_{\mathrm{k}}\right)=\exp .\left(\mathrm{x}_{\mathrm{k}}\right) / \Sigma_{\mathrm{j}} \exp \left(\mathrm{x}_{\mathrm{j}}\right)$, for $\mathrm{j}=1, \ldots, \mathrm{k}$ (dimensions)

In this sense, a three-layer 24-1-1-feed-forward propagation ANN model was trained and developed from 24 predictor variables (age, gender, lipid peroxidation compounds).

Regarding the training type, it was in batch, and the optimization algorithm to estimate the synaptic weights was based on scaled conjugate gradient including an initial lambda and an initial sigma values of 0.0000005 and 0.00005 , respectively, as initial values for the weights and biases to optimize them in successive iterations. 


\subsection{Diagnostic performance evaluation}

Under the previously indicated specifications, several ANN models were developed in each biological matrix, and the averages of them were considered as the most reliable corresponding models.

For diagnostic performance evaluation of the models PLS, SVM with polynomial and radial kernel functions, and ANN, receiver operating characteristic (ROC) curves were constructed from their corresponding validation results, indicating the area under the curve (AUC)-ROC as a parameter that represents the accuracy of each model. For the PLS model, it consisted of cross validation leaving one out, while for the SVM and ANN models, validation consisted of using data sets randomly divided. The corresponding area under the curve (AUC, 95\% confidence interval (CI)), and the optimum cut-off value (the highest sum of sensitivity and specificity) were determined for each model in the prediction of AD. Finally, the diagnostic indices (sensitivity, specificity, positive likelihood ratio $(\mathrm{LR}+)$, negative likelihood ratio $(\mathrm{LR}-)$, diagnostic odds ratio (DOR)) were calculated. For all analysis, a $p<.05$ was considered to indicate a statistically significant difference.

\section{Results}

\subsection{Demographic, clinical and analytical variables}

The demographic and clinical variables for each group of participants are described in Table 1 . All of them showed a non-normal distribution, so medians were compared between groups by means of Mann Whitney test for numerical variables, and Chi-square and Fisher exact tests for categorical variables. The clinical variables (Repeatable Battery for the Assessment of Neuropsychological Status (RBANS), Clinical Dementia Rating (CDR), Functional Activities Questionnaire (FAQ), Mini-Mental State Examination (MMSE), cerebrospinal fluid (CSF) $\beta$-amyloid, CSF total-Tau and CSF phosphorylated-Tau) showed statistically significant differences between MCI-AD and healthy control groups. On the other hand, demographic variables did not present statistically significant differences between both groups except of gender and age, so these variables were taken into account in the subsequent analyses.

The concentrations obtained for each analytical variable (22 analytes) in both matrices (urine, plasma) are summarized in Table 2. As we can see, statistically significant differences between groups were obtained for 17-epi-17- $\mathrm{F}_{2 \mathrm{t}}$-dihomo-IsoP in urine samples, and for $15(R)$ $15-\mathrm{F}_{2 \mathrm{t}}$-IsoP, $\mathrm{PGF}_{2 \alpha}, 4(R S)-4-\mathrm{F}_{4 \mathrm{t}}$-NeuroP, ent-7(RS)-7- $\mathrm{F}_{2 \mathrm{t}}$-dihomo-IsoP, 17-epi-17- $\mathrm{F}_{2 \mathrm{t}}$-dihomo-IsoP, isoprostanes, isofurans, neuroprostanes and neurofurans in plasma samples.

\subsection{Multivariate statistical models}

In this work we developed different multivariate models in order to improve the diagnostic utility of lipid peroxidation products from plasma and urine samples $[9,38]$, since they do not have a high diagnostic capacity individually. For this, different multivariate models based on linear and non-linear regression were developed for each kind of biological sample and they were compared in terms of diagnostic performance.

First, PLS linear regression models were developed. For PLS in urine, in Fig. 1 we can see that the MCI-AD group showed higher levels for the compounds $15(R)-15-\mathrm{F}_{2 \mathrm{t}}$-IsoP, 2,3-dinor-15-epi-15- $\mathrm{F}_{2 \mathrm{t}}$-IsoP, $4(R S)-4-\mathrm{F}_{4 \mathrm{t}}$-NeuroP, ent-7 (RS)-7- $\mathrm{F}_{2 \mathrm{t}}$-dihomo-IsoP, 17-epi- $17-\mathrm{F}_{2 \mathrm{t}}$-dihomo-IsoP, 10-epi-10- $\mathrm{F}_{4 \mathrm{t}}$-NeuroP, $17-\mathrm{F}_{2 \mathrm{t}}$-dihomo-IsoP and neurofurans, as well as higher age and female proportion (Fig. 1a). However, the healthy participants are grouped on the left side of the score plot (Fig. 1b) because they showed lower levels for the previous compounds. Similarly, for PLS in plasma, in Fig. 2 we can see that the MCI-AD group showed higher levels for the compounds $15(R)-15-\mathrm{F}_{2 \mathrm{t}^{-}}$IsoP, $4(R S)-4-\mathrm{F}_{4 \mathrm{t}^{-}}$ NeuroP, neuroprostanes, isoprostanes, ent-7(RS)-7- $\mathrm{F}_{2 \mathrm{t}}$-dihomo-IsoP,
Table 1

Demographic and clinical variables of the studied population.

\begin{tabular}{|c|c|c|c|c|}
\hline \multicolumn{2}{|l|}{ Variable } & $\begin{array}{l}\text { MCI-AD } \\
(n=70)\end{array}$ & $\begin{array}{l}\text { Healthy control } \\
(n=26)\end{array}$ & P-value \\
\hline \multicolumn{2}{|c|}{ Gender (Female, n (\%)) } & $41(58.6 \%)$ & $9(34.6 \%)$ & $0.037^{*}$ \\
\hline \multicolumn{2}{|c|}{ Age (Median, (IQR)) } & $70(68-74)$ & $66(62-70)$ & $0.044^{*}$ \\
\hline \multicolumn{2}{|c|}{ Depression (Yes, n (\%)) } & $9(13 \%)$ & $5(19 \%)$ & 0.566 \\
\hline \multicolumn{2}{|c|}{ Anxiety (Yes, n (\%)) } & $6(9 \%)$ & $2(8 \%)$ & 0.629 \\
\hline \multirow{3}{*}{$\begin{array}{l}\text { Studies levels } \\
\text { (n }(\%))\end{array}$} & Primary & $28(40 \%)$ & $16(61 \%)$ & \multirow[t]{3}{*}{0.173} \\
\hline & Secondary & $20(29 \%)$ & $3(12 \%)$ & \\
\hline & Academic & $22(31 \%)$ & $7(27 \%)$ & \\
\hline \multicolumn{2}{|c|}{$\begin{array}{l}\text { Smoking status (smoker or former } \\
\text { smoker) (n (\%)) }\end{array}$} & $50(71 \%)$ & $13(50 \%)$ & 0.124 \\
\hline \multicolumn{2}{|c|}{ Alcohol consumption (yes, n (\%)) } & $12(17 \%)$ & $2(8 \%)$ & 0.307 \\
\hline \multirow{5}{*}{$\begin{array}{l}\text { Medications (n, } \\
\quad(\%))\end{array}$} & None & $15(22 \%)$ & $8(31 \%)$ & \multirow[t]{5}{*}{0.269} \\
\hline & psychotropic drugs & $3(4 \%)$ & $2(8 \%)$ & \\
\hline & Antihypertensive & $10(14 \%)$ & $7(27 \%)$ & \\
\hline & Statins & $12(17 \%)$ & $3(11 \%)$ & \\
\hline & Two or more & $30(43 \%)$ & $6(23 \%)$ & \\
\hline \multirow{5}{*}{$\begin{array}{l}\text { Comorbidity (n, } \\
(\%))\end{array}$} & None & $18(26 \%)$ & $10(39 \%)$ & \multirow[t]{5}{*}{0.071} \\
\hline & Dyslipemia & $18(26 \%)$ & $3(11 \%)$ & \\
\hline & Hypertension & $10(14 \%)$ & $7(27 \%)$ & \\
\hline & Heart disease & $0(0 \%)$ & $1(4 \%)$ & \\
\hline & Two or more & $24(34 \%)$ & $5(19 \%)$ & \\
\hline \multicolumn{2}{|l|}{ RBANS-DM ${ }^{1}$} & $42(40-49)$ & $100(90-106)$ & $0.000^{*}$ \\
\hline \multicolumn{2}{|l|}{$\mathrm{CDR}^{2}$} & $0.5(0.5-1)$ & $0(0-0)$ & $0.000^{*}$ \\
\hline \multicolumn{2}{|l|}{$\mathrm{FAQ}^{3}$} & $7(2-13)$ & $0(0-0)$ & $0.000^{*}$ \\
\hline \multicolumn{2}{|l|}{$\mathrm{MMSE}^{4}$} & 25 (19-29) & $24(21-27)$ & $0.000^{*}$ \\
\hline \multirow{2}{*}{\multicolumn{2}{|c|}{$\mathrm{CSF}^{5} \beta$-amyloid $\left(\mathrm{pg} \mathrm{mL}^{-1}\right)$}} & 597 & 1186 & $0.000^{*}$ \\
\hline & & $(445-687)$ & $(1033-1403)$ & \\
\hline \multirow{2}{*}{\multicolumn{2}{|c|}{$\operatorname{CSF} \mathrm{t}-\mathrm{Tau}^{6}\left(\mathrm{pg} \mathrm{mL} \mathrm{L}^{-1}\right)$}} & 572 & $202(139-320)$ & $0.000^{*}$ \\
\hline & & $(396-857)$ & & \\
\hline \multicolumn{2}{|c|}{ CSF p-Tau $\left(\mathrm{pg} \mathrm{mL}^{-1}\right)$} & $88(72-111)$ & $49(35-67)$ & $0.000^{*}$ \\
\hline
\end{tabular}

IQR: Interquartile range.

Data were expressed as median (interquartile range (IQR)) for non-parametric continuous variables, and number of cases (percentages) for categorical cases. The statistical calculations to compare between the two groups employed Mann-Whitney test, Chi-Square test and Fisher exact test, respectively.

1 RBANS-DM, Repeatable Battery for the Assessment of Neuropsychological Status- Delayed Memory (Standard Score; cut-off point $<85$ ).

${ }^{2}$ CDR, Clinical Dementia Rating, values: 0, 0.5, 1, 2.

${ }^{3}$ FAQ, Functional Activities Questionnaire (Direct Score; cut-off point $>9$ ).

4 MMSE, Minimental State Examination.

5 CSF, Cerebrospinal fluid.

6 t-Tau, total-Tau.

7 p-Tau, phosphorylated-Tau.

$* p<.05$.

neurofurans and isofurans, as well as higher age and female proportion (Fig. 2a). However, the healthy individuals are grouped in the left side of the score plot (Fig. 2b) due to their lower levels for the previous compounds.

Secondly, SVM models with radial and polynomial kernel functions were developed from results in plasma and urine samples. Non linear functions were used in order to obtain a better classification of the participants.

Thirdly, non-linear regression models based on ANN were developed for urine and plasma samples in order to classify the two groups of participants. As shown in Fig. 3, 22 analytes, gender and age were included in the input layer. For the hidden and output layers, the transfer functions were hyperbolic tangent and normalized exponential functions, respectively.

\subsection{Diagnostic performance for the statistical multivariate developed models}

The diagnostic performance of each model was estimated from the corresponding ROC curves (Fig. 4). In urine samples, the ANN model provided an AUC of 0.839 (CI 95\%, 0.746-0.933), while for the PLS model it was 0.653 (CI 95\%, 0.526-0.780), and for the SVM models it 
Table 2

Concentrations determined by UPLC-MS/MS for each analyte in plasma and urine samples from MCI-AD and healthy control participants.

\begin{tabular}{|c|c|c|c|c|c|c|c|c|c|c|c|c|c|c|}
\hline \multirow[t]{4}{*}{ Analyte } & \multicolumn{7}{|c|}{ Plasma $\left(\mathrm{nmol} \mathrm{L}^{-1}\right)$} & \multicolumn{7}{|c|}{ Urine (ng mg creatinine ${ }^{-1}$ ) } \\
\hline & \multicolumn{3}{|c|}{ MCI-AD $(\mathrm{n}=70)$} & \multicolumn{3}{|c|}{ Healthy control $(n=26)$} & \multirow[t]{3}{*}{$P$-value } & \multicolumn{3}{|c|}{ MCI-AD $(\mathrm{n}=70)$} & \multicolumn{3}{|c|}{ Healthy control $(\mathrm{n}=26)$} & \multirow[t]{3}{*}{ P-value } \\
\hline & \multirow[t]{2}{*}{ Median } & \multicolumn{2}{|l|}{ quartile } & \multirow[t]{2}{*}{ Median } & \multicolumn{2}{|c|}{ quartile } & & \multirow[t]{2}{*}{ Median } & \multicolumn{2}{|c|}{ quartile } & \multirow[t]{2}{*}{ Median } & \multicolumn{2}{|c|}{ quartile } & \\
\hline & & 1 st & $3 r d$ & & $1 \mathrm{st}$ & $3 r d$ & & & $1 \mathrm{st}$ & $3 r d$ & & $1 \mathrm{st}$ & $3 r d$ & \\
\hline $15(R)-15-\mathrm{F}_{2 \mathrm{t}}$-IsoP & 0.30 & 0.23 & 0.46 & 0.20 & 0.15 & 0.26 & $0.000^{*}$ & 0.69 & 0.47 & 1.42 & 0.71 & 0.49 & 1.00 & 0.830 \\
\hline $\mathrm{PGE}_{2}$ & 0.05 & 0.00 & 0.13 & 0.05 & 0.00 & 0.10 & 0.520 & 1.93 & 0.43 & 3.48 & 1.85 & 0.92 & 4.62 & 0.615 \\
\hline 2,3-dinor-15-epi-15- $\mathrm{F}_{2 \mathrm{t}}$-IsoP & 0.00 & 0.00 & 0.03 & 0.00 & 0.00 & 0.00 & 0.067 & 0.73 & 0.49 & 1.22 & 0.65 & 0.47 & 1.12 & 0.458 \\
\hline 15-keto-15- $\mathrm{E}_{2 \mathrm{t}}$-IsoP & 0.15 & 0.00 & 0.35 & 0.13 & 0.04 & 0.27 & 0.874 & 0.92 & 0.51 & 1.46 & 0.88 & 0.52 & 1.65 & 0.644 \\
\hline 15-keto-15- $\mathrm{F}_{2 \mathrm{t}}$-IsoP & 0.23 & 0.09 & 0.35 & 0.23 & 0.14 & 0.28 & 0.599 & 0.79 & 0.16 & 1.85 & 1.52 & 0.60 & 2.20 & 0.094 \\
\hline $15-\mathrm{E}_{2 \mathrm{t}}$-IsoP & 0.26 & 0.12 & 0.43 & 0.19 & 0.09 & 0.28 & 0.320 & 0.18 & 0.05 & 1.29 & 0.19 & 0.06 & 0.76 & 0.830 \\
\hline $5-\mathrm{F}_{2 \mathrm{t}}-\mathrm{IsoP}$ & 0.78 & 0.40 & 1.26 & 0.99 & 0.73 & 1.23 & 0.362 & 2.66 & 1.61 & 4.85 & 2.70 & 1.77 & 3.85 & 0.817 \\
\hline $15-\mathrm{F}_{2 \mathrm{t}}$-IsoP & 0.02 & 0.01 & 0.04 & 0.02 & 0.02 & 0.03 & 0.638 & 0.01 & 0.00 & 0.02 & 0.01 & 0.00 & 0.02 & 0.113 \\
\hline $\mathrm{PGF}_{2 \alpha}$ & 0.51 & 0.24 & 0.76 & 0.74 & 0.48 & 0.94 & $0.008^{*}$ & 3.67 & 2.69 & 7.90 & 2.98 & 2.34 & 4.98 & 0.295 \\
\hline $4(R S)-4-\mathrm{F}_{4 \mathrm{t}}-$ NeuroP & 1.14 & 0.96 & 1.33 & 1.03 & 0.00 & 1.13 & $0.003^{*}$ & 0.91 & 0.67 & 1.40 & 0.72 & 0.50 & 1.05 & 0.051 \\
\hline 1a,1b-dihomo-PGF $2 \alpha$ & 0.00 & 0.00 & 0.00 & 0.00 & 0.00 & 0.00 & 0.784 & 1.26 & 0.61 & 2.35 & 1.63 & 1.01 & 2.32 & 0.232 \\
\hline 10-epi-10- $\mathrm{F}_{4 \mathrm{t}}$-NeuroP & 0.08 & 0.03 & 0.15 & 0.09 & 0.03 & 0.14 & 0.731 & 0.03 & 0.00 & 0.06 & 0.01 & 0.00 & 0.04 & 0.094 \\
\hline $14(R S)-14-\mathrm{F}_{4 \mathrm{t}}-$ NeuroP & 0.53 & 0.06 & 1.03 & 0.60 & 0.00 & 1.74 & 0.671 & 1.22 & 0.76 & 2.38 & 1.37 & 0.78 & 1.98 & 0.837 \\
\hline ent-7(RS)-7- $\mathrm{F}_{2 \mathrm{t}}$-dihomo-IsoP & 0.10 & 0.05 & 0.15 & 0.05 & 0.04 & 0.08 & $0.002^{*}$ & 0.32 & 0.13 & 0.60 & 0.29 & 0.21 & 0.39 & 1.000 \\
\hline $17-\mathrm{F}_{2 \mathrm{t}}$-dihomo-IsoP & 0.00 & 0.00 & 0.00 & 0.00 & 0.00 & 0.00 & 0.555 & 0.08 & 0.00 & 0.36 & 0.10 & 0.00 & 0.23 & 0.625 \\
\hline 17-epi-17- $\mathrm{F}_{2 \mathrm{t}}$-dihomo-IsoP & 0.03 & 0.00 & 0.05 & 0.00 & 0.00 & 0.01 & $0.015^{*}$ & 0.01 & 0.00 & 0.06 & 0.00 & 0.00 & 0.00 & $0.019^{*}$ \\
\hline $17(R S)$-10-epi-SC- $\Delta^{15}$-11-dihomo-IsoF & 0.00 & 0.00 & 0.00 & 0.00 & 0.00 & 0.00 & 0.164 & 0.03 & 0.00 & 0.11 & 0.05 & 0.02 & 0.08 & 0.330 \\
\hline $7(R S)-S T-\Delta^{8}$-11-dihomo-IsoF & 0.04 & 0.03 & 0.08 & 0.09 & 0.02 & 0.16 & 0.067 & 0.00 & 0.00 & 0.02 & 0.00 & 0.00 & 0.03 & 0.849 \\
\hline Neurofurans $\mathrm{a}^{\mathrm{a}}$ & 0.09 & -0.05 & 0.17 & -0.10 & -0.15 & 0.07 & $0.000^{*}$ & 3.13 & 1.76 & 6.62 & 4.15 & 2.51 & 5.95 & 0.356 \\
\hline Isofurans ${ }^{\mathrm{a}}$ & 0.09 & 0.07 & 0.12 & 0.07 & 0.06 & 0.09 & $0.013^{*}$ & 4.36 & 2.53 & 7.25 & 4.29 & 3.37 & 9.64 & 0.343 \\
\hline Neuroprostanes ${ }^{\text {a }}$ & -0.22 & -0.70 & 0.19 & -0.65 & -0.76 & -0.48 & $0.010^{*}$ & 3.52 & 2.25 & 4.97 & 3.77 & 2.02 & 6.17 & 0.650 \\
\hline Isoprostanes $^{\mathrm{a}}$ & 0.30 & 0.22 & 0.39 & 0.20 & 0.17 & 0.27 & $0.000^{*}$ & 6.20 & 3.82 & 12.37 & 7.30 & 4.67 & 11.45 & 0.491 \\
\hline
\end{tabular}

$* \mathrm{p}<.05$.

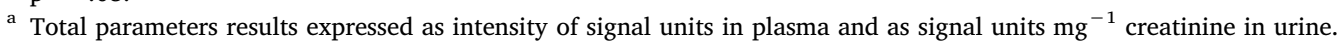

was 0.644 (CI 95\%, 0.539-0.749) with the polynomial function and 0.659 (CI 95\%, 0.558-0.759) with the radial function. Similarly, in plasma samples, the ANN model provided an AUC of 0.882 (CI 95\%, 0.814-0.949), while for PLS it was 0.765 (CI 95\%, 0.633-0.868), and for SVM models it was 0.817 (CI 95\%, 0.712-0.922) with the polynomial function and 0.827 (CI 95\%, 0.739-0.915) with the radial function. Therefore, ANN models provided better diagnostic accuracy than PLS and SVM models in both matrices. Moreover, plasma matrix showed higher diagnostic accuracy than urine.

From the estimated optimal cut-off values, the diagnostic indices in the prediction of early $\mathrm{AD}$ were calculated for each developed model in plasma and urine samples (Table 3). For urine, the ANN model provided a sensitivity of $80.9 \%$, while its specificity was $76.9 \%$. In addition, DOR value for ANN model in urine revealed that there was strong association between the model results and the AD occurrence. Regarding the ANN model in plasma samples, it provided a sensitivity of $88.2 \%$, while its specificity was $76.9 \%$. This model also showed an elevated DOR value that supported its diagnostic value. DOR values were quite similar among plasma models, but ANN model showed better accuracy (AUCROC 0.882) than PLS (AUC-ROC 0.765) and SVM (AUC-ROC 0.827). Moreover, ANN model showed better sensitivity and a satisfactory balance between sensitivity and specificity. ANN model showed better balance, obtaining a higher number of participants correctly classified. By contrast, PLS model showed high specificity but low sensitivity, classifying the AD participants as healthy subjects; while SVM model showed high sensitivity but low specificity, classifying the healthy subjects as AD patients. In general, for both matrices, the PLS model was the most specific, the SVM model was the most sensitive, and the ANN model showed the best balance of sensitivity/specificity.

\section{Discussion}

Some of the analytes studied in this work showed statistically significant differences, such as 17-epi-17- $\mathrm{F}_{2 \mathrm{t}}$-dihomo-IsoP in urine samples, and $15(R)-15-\mathrm{F}_{2 \mathrm{t}^{-}} \mathrm{IsoP}, \quad \mathrm{PGF}_{2 \alpha}, 4(R S)-4-\mathrm{F}_{4 \mathrm{t}^{-}}-$NeuroP, ent-7(RS)-7- $\mathrm{F}_{2 \mathrm{t}^{-}}$
dihomo-IsoP, 17-epi-17- $\mathrm{F}_{2 \mathrm{t}}$-dihomo-IsoP, isoprostanes, isofurans, neuroprostanes and neurofurans in plasma samples. Nevertheless, each analyte individually did not provide a reliable $\mathrm{AD}$ diagnosis. In contrast, a multivariate model based on ANN showed better accuracy than PLS and SVM models, and analytes from plasma samples were more useful than those in urine samples to achieve a reliable $\mathrm{AD}$ diagnosis.

Some studies found lipid peroxidation products as biomarkers for $\mathrm{AD}$ diagnosis, and most of them were based on individual biomarkers, such as lipid peroxidation end products [39] or TBARS [40]. However, multivariate models could reflect the oxidative stress status of patients better, showing superior diagnostic indices and higher accuracy. Specifically, a previous work developed an ANN model based on different $\mathrm{AD}$ risk factors studied the predictive value of these factors [35]. It showed high capacity to integrate different data and achieve a general evaluation. Other developed ANN models to diagnose AD or MCI were based on image, genetics, neuropsychology or other biomarkers $[25,41]$, but the present study is the first one using lipid peroxidation compounds as biomarkers. In general, previous studies based on ANN showed model accuracies around 90\%, similar to our results. Also, PLS models have been developed for AD diagnosis. They were mainly based on gene expression and neuroimaging [42-44], but none of them was based on our set of lipid peroxidation products. In addition, a previous study for MCI diagnosis compared PLS model to other statistical tests, such as Random Forest showing the higher PLS diagnostic power [45].

The diagnostic indices obtained for each model in the present study indicated that the ANN model in both matrices showed a satisfactory accuracy ( $>80 \%$ ). In addition, the plasma ANN model showed, in general, better diagnostic indices than the urine model, corroborating previous studies in the literature [46,47]. Specifically, the ANN model based on the plasma levels of lipid peroxidation products showed high DOR value, sensitivity, and accuracy, as well as, satisfactory specificity, so it is considered a reliable diagnostic model. In this sense, Quintana et al. also found that ANN models showed better discriminant capacity than linear models in AD diagnosis [26]. AD is a complex disease process in which multiple factors are involved and that could be the 

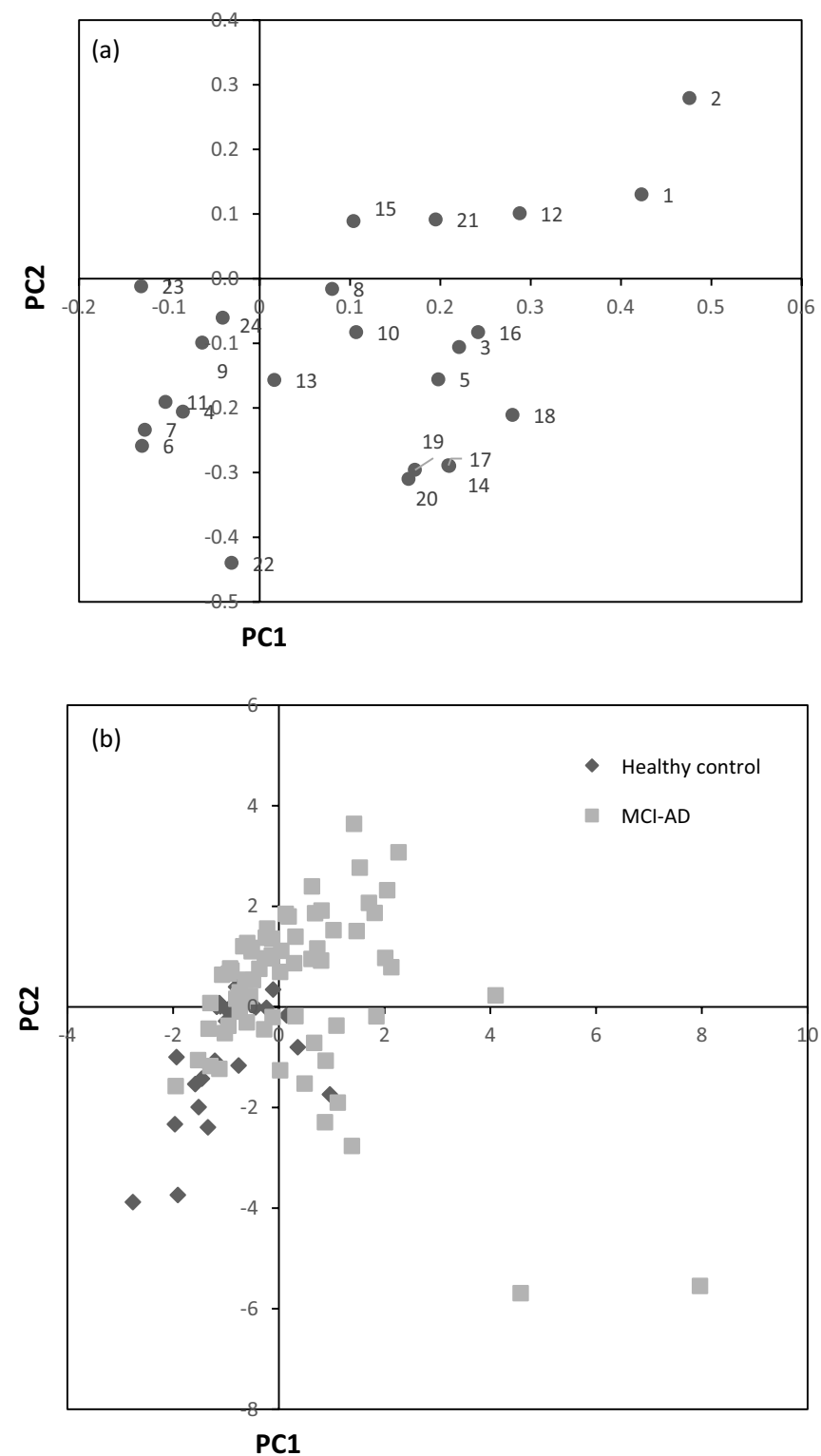

Fig. 1. Plots representing results of the partial least squares regression model in urine samples. (a) Loadings plot. 1: Gender; 2: Age; 3: 15(R)-15- $\mathrm{F}_{2 \mathrm{t}} \mathrm{-I}-\mathrm{Iso}$; 4 : $\mathrm{PGE}_{2}$; 5: 2,3-dinor-15-epi-15- $\mathrm{F}_{2 \mathrm{t}^{-}}$IsoP; 6: 15-keto-15-E 2 -IsoP; 7: 15-keto-15- $\mathrm{F}_{2 \mathrm{t}^{-}}$ IsoP; 8: 15- $\mathrm{E}_{2 \mathrm{t}}$-IsoP; 9: 5- $\mathrm{F}_{2 \mathrm{t}}-\mathrm{IsoP} ; 10$ : 15- $\mathrm{F}_{2 \mathrm{t}}-\mathrm{IsoP} ; 11: \mathrm{PGF}_{2 \alpha} ; 12: 4(R S)-\mathrm{F}_{4 \mathrm{t}^{-}}$

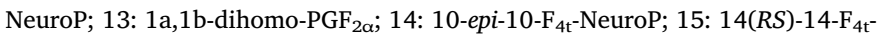
NeuroP; 16: ent-7(RS)-7- $\mathrm{F}_{2 \mathrm{t}}$-dihomo-IsoP; 17: 17- $\mathrm{F}_{2 \mathrm{t}}$-dihomo-IsoP; 18: 17-epi-

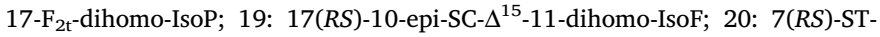
$\Delta^{8}$-11-dihomo-IsoF; 21: neurofurans; 22: isofurans; 23: neuroprostanes; 24: isoprostanes. (b) Scores plot.

reason why non-linear regression models showed a better predictive capacity than those models based on linear regression [35].

Regarding the biological matrix, the proposed ANN diagnostic model in plasma samples constitutes a promising minimally invasive approach that could avoid, in some cases, the current diagnostic methods, which involve invasive sampling and expensive techniques [48]. In this sense, the ANN models have a satisfactory diagnostic capacity, and they are able to classify the participants into healthy and MCI-AD with high accuracy in both matrices as an early screening tool.

\section{Conclusion}

The non-linear regression model based on ANN explained the non-
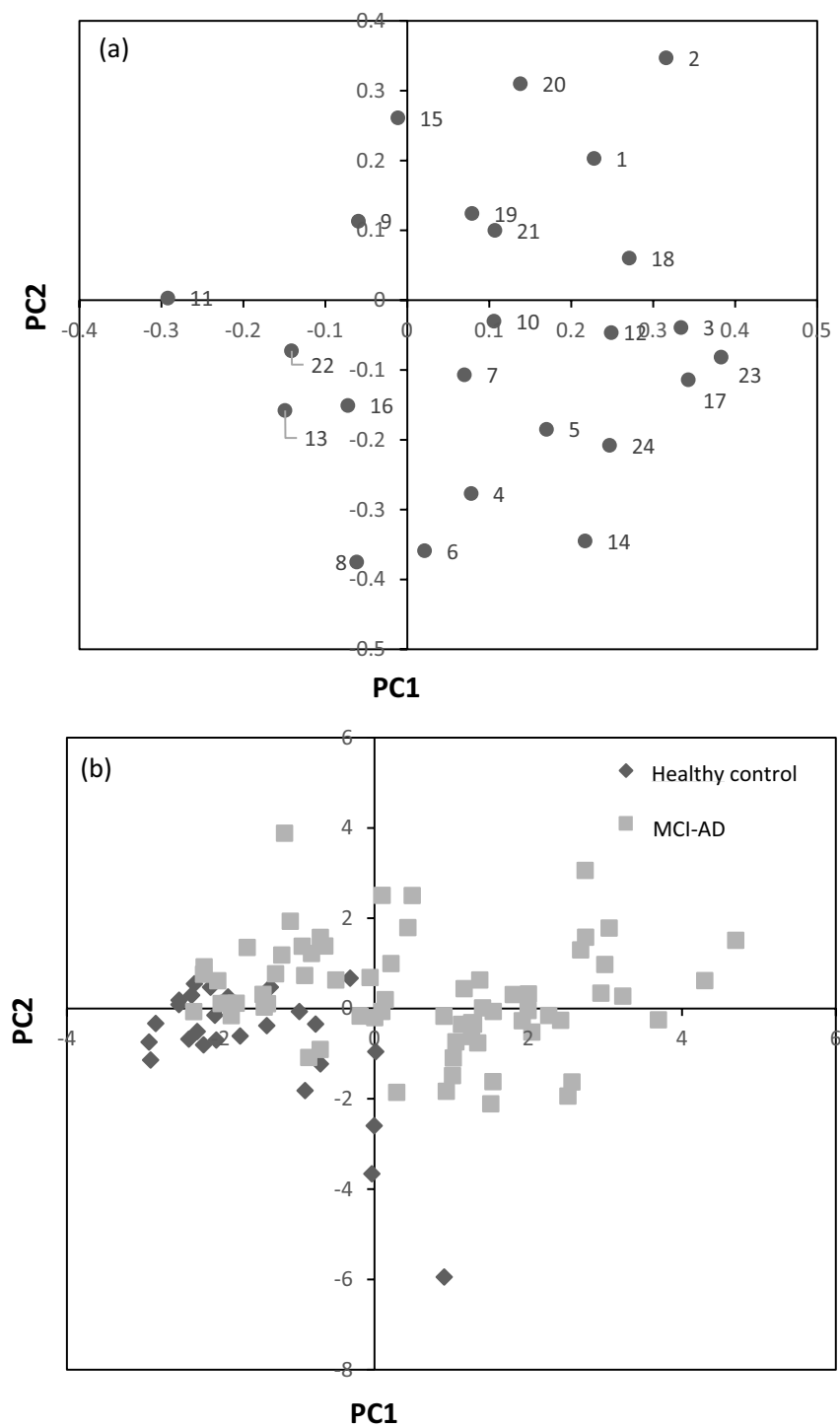

Fig. 2. Plots representing results of the partial least squares regression model in plasma samples. (a) Loadings plot. 1: Gender; 2: Age; 3: 15(R)-15- $\mathrm{F}_{2 \mathrm{t}}$-IsoP; 4: $\mathrm{PGE}_{2}$; 5: 2,3-dinor-15-epi-15- $\mathrm{F}_{2 \mathrm{t}}$-IsoP; 6: 15-keto-15- $\mathrm{E}_{2 \mathrm{t}}$-IsoP; 7: 15-keto-15- $\mathrm{F}_{2 \mathrm{t}}{ }^{-}$

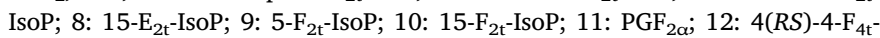
NeuroP; 13: 1a,1b-dihomo-PGF $2 \alpha$; 14: neuroprostanes; 15: 10-epi-10- $\mathrm{F}_{4 \mathrm{t}}{ }^{-}$

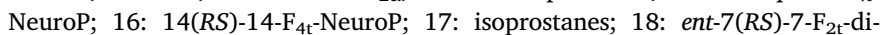
homo-IsoP; 19: 17- $\mathrm{F}_{2 \mathrm{t}}$-dihomo-IsoP; 20: 17-epi-17- $\mathrm{F}_{2 \mathrm{t}}$-dihomo-IsoP; 21: 17(RS)10-epi-SC- $\Delta^{15}$-11-dihomo-IsoF; 22: 7(RS)-ST- $\Delta^{8}$-11-dihomo-IsoF; 23: neurofurans; 24: isofurans. (b) Scores plot.

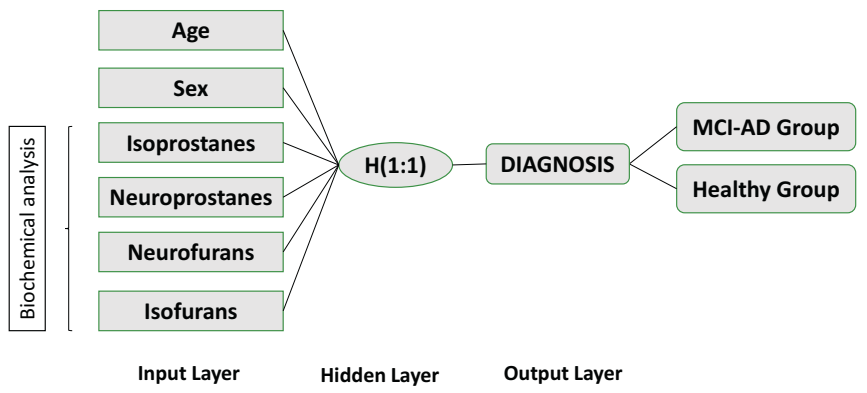

Fig. 3. General structure of the developed neural network for the prediction of early $\mathrm{AD}$ consisting of 24 input variables, 1 hidden layer with 1 node, and 1 output variable. 


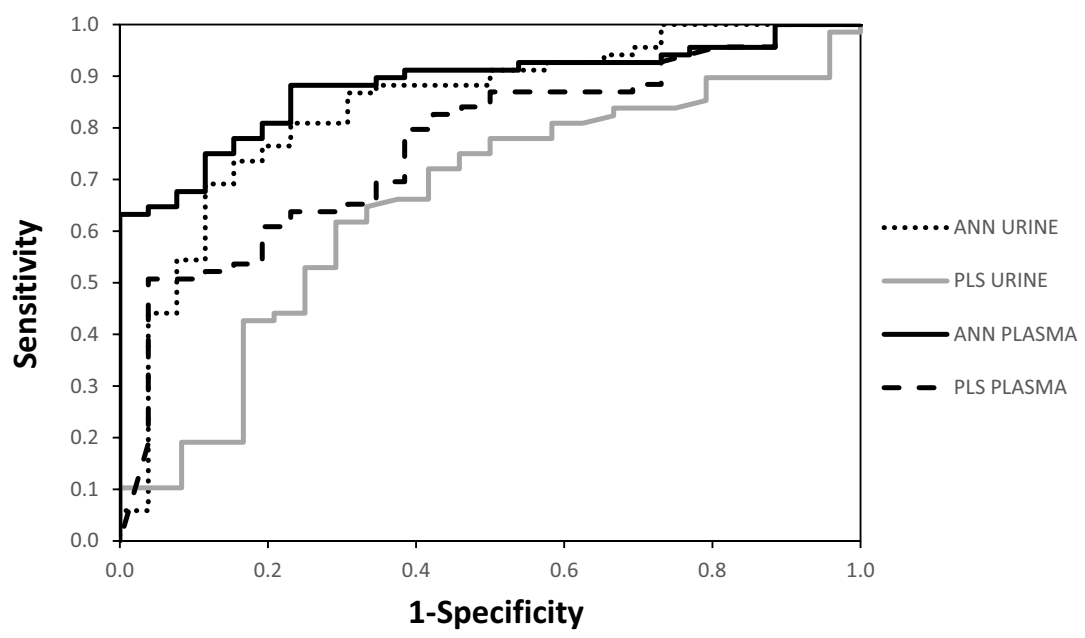

Fig. 4. Receiver operating Characteristic curves for PLS and ANN models in plasma and urine samples.

Table 3

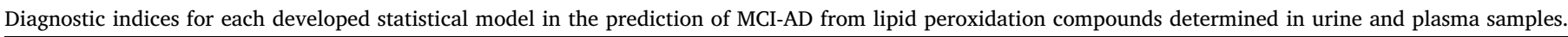

\begin{tabular}{|c|c|c|c|c|c|c|c|c|}
\hline & \multicolumn{4}{|l|}{ Urine } & \multicolumn{4}{|l|}{ Plasma } \\
\hline & \multirow[t]{2}{*}{ PLS } & \multirow[t]{2}{*}{ ANN } & \multicolumn{2}{|l|}{ SVM } & \multirow[t]{2}{*}{ PLS } & \multirow[t]{2}{*}{ ANN } & \multicolumn{2}{|l|}{ SVM } \\
\hline & & & Radial & Polynomial & & & Radial & Polynomial \\
\hline AUC (CI 95\%) & $\begin{array}{l}0.653 \\
(0.526-0.780)\end{array}$ & $\begin{array}{l}0.839 \\
(0.746-0.933)\end{array}$ & $\begin{array}{l}0.659 \\
(0.558-0.759)\end{array}$ & $\begin{array}{l}0.644 \\
(0.539-0.749)\end{array}$ & $\begin{array}{l}0.765 \\
(0.663-0.868)\end{array}$ & $\begin{array}{l}0.882 \\
(0.814-0.949)\end{array}$ & $\begin{array}{l}0.827 \\
(0.739-0.915)\end{array}$ & $\begin{array}{l}0.817 \\
(0.712-0.922)\end{array}$ \\
\hline $\begin{array}{c}\text { Sensitivity (\%, } \\
\text { CI 95\%) }\end{array}$ & $63.2(51.4-73.7)$ & $80.9(70.0-88.5)$ & 92.9 (68.5-98.7) & 92.3 (66.7-98.6) & $50.7(39.2-62.2)$ & $88.2(78.5-93.9)$ & $92.3(66.7-98.6)$ & $100.0(77.2-100)$ \\
\hline $\begin{array}{c}\text { Specificity (\%, } \\
\text { CI 95\%) }\end{array}$ & $70.8(50.8-85.1)$ & $76.9(57.9-89.0)$ & $11.1(2.0-43.5)$ & $37.5(13.7-69.4)$ & 96.2 (81.1-99.3) & 76.9 (57.9-89.0) & $50.0(21.5-78.5)$ & $25.0(7.1-59.1)$ \\
\hline $\mathrm{LR}+(\mathrm{CI} 95 \%)$ & $2.17(1.13-4.15)$ & $3.50(1.72-7.14)$ & $1.04(0.80-1.37)$ & $1.48(0.84-2.58)$ & $\begin{array}{l}13.19 \\
(1.90-91.40)\end{array}$ & $3.82(1.89-7.75)$ & $1.85(0.91-3.76)$ & 1.33 (0.89-1.99) \\
\hline LR- (CI 95\%) & $0.52(0.36-0.74)$ & $0.25(0.15-0.41)$ & $0.64(0.07-6.06)$ & $0.21(0.03-1.49)$ & $0.51(0.40-0.66)$ & $0.15(0.08-0.30)$ & $0.15(0.02-1.08)$ & - \\
\hline DOR (CI 95\%) & $\begin{array}{l}4.18 \\
(1.52-11.46)\end{array}$ & $\begin{array}{l}14.10 \\
(4.72-42.13)\end{array}$ & $\begin{array}{l}1.63 \\
(0.09-29.78)\end{array}$ & $\begin{array}{l}7.20 \\
(0.60-87.02)\end{array}$ & $\begin{array}{l}25.74 \\
(3.30-200.67)\end{array}$ & $\begin{array}{l}25.00 \\
(7.73-80.81)\end{array}$ & $\begin{array}{l}12.0 \\
(1.02-141.34)\end{array}$ & - \\
\hline
\end{tabular}

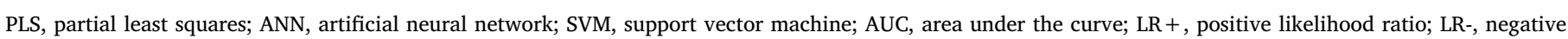
likelihood ratio; CI, confidence interval; DOR, diagnostic odds ratio.

linear relationship between the levels of lipid peroxidation compounds and the diagnosis of a complex pathophysiological process, such as $\mathrm{AD}$, constituting a promising screening approach. Specifically, the developed ANN model in plasma samples showed high accuracy and suitable diagnostic indices in early $\mathrm{AD}$ prediction. Nevertheless, further research will need to be carried out to clinically validate this diagnostic model. This approach constitutes a significant advance in early AD diagnosis, using minimally invasive sampling techniques, and offers important economic cost reduction for the public health system.

\section{Funding}

This work was supported by the Instituto de Salud Carlos III (Miguel Servet I Project (CP16/00082)) (Spanish Ministry of Economy and Competitiveness, and European Regional Development Fund).

\section{Declaration of Competing Interest}

None.

\section{Acknowledgement}

CC-P acknowledges a "Miguel Servet I" Grant (CP16/00082) from the Instituto Carlos III (ISCIII, Spanish Ministry of Economy and Competitiveness). CP-B acknowledges a pre-doctoral Grant (associated to "Miguel Servet" project CP16/00082) from the ISCIII (Spanish Ministry of Economy, Industry and Competitiveness).

The authors are grateful for the professional English language editing to Mr. Arash Javadinejad, English Instructor and Publication Editor at the Instituto de Investigación Sanitaria La Fe, Valencia, Spain.

\section{References}

[1] M. Prince, E. Albanese, M. Guerchet, M. Prina, World Alzheimer Report 2014: Dementia and Risk Reduction an Analysis of Protective and Modifiable Factors, (2014).

[2] W. Huang, X. Zhang, W.W. Chen, Role of oxidative stress in Alzheimer's disease, Biomed. Rep. 4 (2016) 519-522.

[3] R. Sultana, M. Perluigi, D. Allan Butterfield, Lipid peroxidation triggers neurodegeneration: a redox proteomics view into the Alzheimer disease brain, Free Radic. Biol. Med. 62 (2013) 157-169.

[4] Z. Chen, C. Zhong, Oxidative stress in Alzheimer's disease, Neurosci. Bull. 30 (2014) $271-281$.

[5] C. Peña-Bautista, M. Baquero, M. Vento, C. Cháfer-Pericás, Free radicals in Alzheimer's disease: lipid peroxidation biomarkers, Clin. Chim. Acta 491 (2019) 85-90.

[6] M. Czerska, M. Zieliński, J. Gromadzińska, Isoprostanes - a novel major group of oxidative stress markers, Int. J. Occup. Med. Environ. Health 29 (2016) 179-190.

[7] T.J. Montine, E.R. Peskind, J.F. Quinn, A.M. Wilson, K.S. Montine, D. Galasko, Increased cerebrospinal fluid F2-isoprostanes are associated with aging and latent Alzheimer's disease as identified by biomarkers, NeuroMolecular Med. 13 (2011) 37-43.

[8] F.B. Sirin, D. Kumbul Doğuç, H. Vural, I. Eren, I. Inanli, R. Sütçü, N. Delibaş, Plasma 8-isoPGF2 $\alpha$ and serum melatonin levels in patients with minimal cognitive impairment and Alzheimer disease, Turk. J. Med. Sci. 45 (2015) 1073-1077. 
[9] A. García-Blanco, C. Peña-Bautista, C. Oger, C. Vigor, J.M. Galano, T. Durand, N. Martín-Ibáñez, M. Baquero, M. Vento, C. Cháfer-Pericás, Reliable determination of new lipid peroxidation compounds as potential early Alzheimer Disease biomarkers, Talanta. 184 (2018) 193-201.

[10] S. Hartmann, T.B. Ledur Kist, A review of biomarkers of Alzheimer's disease in noninvasive samples, Biomark. Med 12 (2018) 677-690.

[11] L. Roberts, J.P. Fessel, The biochemistry of the isoprostane, neuroprostane, and isofuran pathways of lipid peroxidation, Chem. Phys. Lipids 128 (2004) 173-186.

[12] B. Olsson, R. Lautner, U. Andreasson, A. Öhrfelt, E. Portelius, M. Bjerke, M.H.C. er Rosén, C. Olsson, G. Strobel, E. Wu, K. Dakin, M. Petzold, K. Blennow, H. Zetterberg, CSF and blood biomarkers for the diagnosis of Alzheimer's disease: a systematic review and meta-analysis, Lancet 15 (2016) 473-484.

[13] R. Wurtman, Biomarkers in the diagnosis and management of Alzheimer's disease, Metabolism 64 (2015) S47-S50.

[14] C. Ibáñez, C. Simó, P.J. Martín-Álvarez, M. Kivipelto, B. Winblad, A. CedazoMínguez, A. Cifuentes, Toward a predictive model of Alzheimer's disease progression using capillary electrophoresis-mass spectrometry metabolomics, Anal. Chem. 84 (2012) 8532-8540.

[15] A. Alexiou, V.D. Mantzavinos, N.H. Greig, M.A. Kamal, A Bayesian model for the prediction and early diagnosis of Alzheimer's disease, Front. Aging Neurosci. 31 (2017) 69-77.

[16] B. Dębska, B. Guzowska-Świder, Application of artificial neural network in food classification, Anal. Chim. Acta 705 (2011) 283-291.

[17] D. Zafeiris, S. Rutella, G.R. Ball, An artificial neural network integrated pipeline for biomarker discovery using Alzheimer's disease as a case study, Comput. Struct. Biotech. J. 16 (2018) 77-87.

[18] A. Alibakshi, Strategies to develop robust neural network models: prediction of flash point as a case study, Anal. Chim. Acta 1026 (2018) 69-76.

[19] L.A. Berrueta, R.M. Alonso-Salces, K. Héberger, Supervised pattern recognition in food analysis, J. Chromatogr. A 1158 (2007) 196-214.

[20] W.D. Hong, X.R. Chen, S.Q. Jin, Q.K. Huang, Q.H. Zhu, J.Y. Pan, Use of an artificial neural network to predict persistent organ failure in patients with acute pancreatitis, Clinics (Sao Paulo) 68 (2013) 27-31.

[21] J. Yazdani Charati, G. Janbabaei, N. Alipour, S. Mohammadi, S. Ghorbani Gholiabad, A. Fendereski, Survival prediction of gastric cancer patients by Artificial Neural Network model, Gastroenterol. Hepatol. Bed. Bench. 11 (2018) 110-117.

[22] L. He, H. Li, S.K. Holland, W. Yuan, M. Altaye, N.A. Parikh, Early prediction of cognitive deficits in very preterm infants using functional connectome data in an artificial neural network framework, Neuroimage Clin. 18 (2018) 290-297.

[23] D. Devikanniga, R. Joshua Samuel Raj, Classification of osteoporosis by artificial neural network based on monarch butterfly optimisation algorithm, Healthc. Technol. Lett. 5 (2018) 70-75.

[24] A. Catic, L. Gurbeta, A. Kurtovic-Kozaric, S. Mehmedbasic, A. Badnjevic, Application of Neural Networks for classification of Patau, Edwards, Down, Turner and Klinefelter Syndrome based on first trimester maternal serum screening data, ultrasonographic findings and patient demographics, BMC Med. Genet. 11 (2018) 19.

[25] A.J.C.C. Lins, M.T.C. Muniz, A.N.M. Garcia, A.V. Gomes, R.M. Cabral, C.J.A. BastosFilho, Using artificial neural networks to select the parameters for the prognostic of mild cognitive impairment and dementia in elderly individuals, Comput. Methods Prog. Biomed. 152 (2017) 93-104.

[26] M. Quintana, J. Guàrdia, G. Sánchez-Benavides, M. Aguilar, J.L. Molinuevo, A. Robles, M.S. Barquero, C. Antúnez, C. Martínez-Parra, A. Frank-García, M. Fernández, R. Blesa, J. Peña-Casanova, Neuronorma Study Team, Using artificial neural networks in clinical neuropsychology: high performance in mild cognitive impairment and Alzheimer's disease, J. Clin. Exp. Neuropsychol. 34 (2012) 195-208.

[27] G. Li, X. Zhou, J. Liu, Y. Chen, H. Zhang, Y. Chen, J. Liu, H. Jiang, J. Yang, S. Nie, Comparison of three data mining models for prediction of advanced schistosomiasis prognosis in the Hubei provine, cPLoS Negl. Trop. Dis. 12 (2018) e0006262.

[28] E. Grossi, M.P. Buscema, D. Snowdon, P. Antuono, Neuropathological findings processed by artificial neural networks (ANNs) can perfectly distinguish Alzheimer's patients from controls in the Nun Study, BMC Neurol. 7 (2007) 15.

[29] F. Bertè, G. Lamponi, R.S. Calabrò, P. Bramanti, Elman neural network for the early identification of cognitive impairment in Alzheimer's disease, Funct. Neurol. 29 (2014) 57-65.
[30] X. Deng, K. Li, S. Liu, Preliminary study on application of artificial neural network to the diagnosis of Alzheimer's disease with magnetic resonance imaging, Chin. Med. J. 112 (1999) 232-237.

[31] H.F. da Silva Lopes, J.M. Abe, R. Anghinah, Application of paraconsistent artificial neural networks as a method of aid in the diagnosis of Alzheimer disease, J. Med. Syst. 34 (2010) 1073-1081.

[32] J.M. Abe, H.F.D.S. Lopes, R. Anghinah, Paraconsistent artificial neural networks and Alzheimer disease: a preliminary study, Dement. Neuropsychol. 1 (2007) 241-247.

[33] M. Buscema, E. Grossi, D. Snowdon, P. Antuono, M. Intraligi, G. Maurelli, R. Savarè, Artificial neural networks and artificial organisms can predict Alzheimer pathology in individual patients only on the basis of cognitive and functional status, Neuroinformatics. 2 (2004) 399-416.

[34] E. Ryzhikova, O. Kazakov, L. Halamkova, D. Celmins, P. Malone, E. Molho, E.A. Zimmerman, I.K. Lednev, Raman spectroscopy of blood serum for Alzheimer's disease diagnostics: specificity relative to other types of dementia, J. Biophotonics 8 (2015) 584-596.

[35] M. Tabaton, P. Odetti, S. Cammarata, R. Borghi, F. Monacelli, C. Caltagirone, P. Bossù, M. Buscema, E. Grossi, Artificial neural networks identify the predictive values of risk factors on the conversion of amnestic mild cognitive impairment, $\mathrm{J}$. Alzheimers Dis. 19 (2010) 1035-1040.

[36] E. Grossi, A. Stoccoro, P. Tannorella, L. Migliore, F. Coppedè, Artificial neural networks link one-carbon metabolism to gene-promoter methylation in Alzheimer's disease, J. Alzheimers Dis. 53 (2016) 1517-1522.

[37] C.R. Jack, D.A. Bennett, K. Blennow, M.C. Carrillo, B. Dunn, S.B. Haeberlein, D.M. Holtzman, W. Jagust, F. Jessen, J. Karlawish, E. Liu, J.L. Molinuevo, T. Montine, C. Phelps, K.P. Rankin, C.C. Rowe, P. Scheltens, E. Siemers, H.M. Snyder, R. Sperling, NIA-AA Research Framework: toward a biological definition of Alzheimer's disease, Alzheimers Dement. 14 (2018) 535-562.

[38] C. Peña-Bautista, C. Vigor, J.M. Galano, C. Oger, T. Durand, I. Ferrer, A. Cuevas, R. López-Cuevas, M. Baquero, M. López-Nogueroles, M. Vento, D. Hervás, A. GarcíaBlanco, C. Cháfer-Pericás, Plasma lipid peroxidation biomarkers for early and noninvasive Alzheimer Disease detection, Free Radic. Biol. Med. 124 (2018) 388-394.

[39] Z. Chmatalova, M. Vyhnalek, J. Laczo, J. Hort, R. Pospisilova, M. Pechova, A. Skoumalova, Relation of plasma selenium and lipid peroxidation end products in patients with Alzheimer's disease, Physiol. Res. 66 (2017) 1049-1056.

[40] M.C. Puertas, J.M. Martínez-Martos, M.P. Cobo, M.P. Carrera, M.D. Mayas, M.J. Ramírez-Expósito, Plasma oxidative stress parameters in men and women with early stage Alzheimer type dementia, Exp. Gerontol. 47 (2012) 625-630.

[41] J. Tang, L. Wu, H. Huang, J. Feng, Y. Yuan, Y. Zhou, P. Huang, Y. Xu, C. Yu, Back propagation artificial neural network for community Alzheimer's disease screening in China, Neural Regen. Res. 8 (2013) 270-276.

[42] B.B. Booij, T. Lindahl, P. Wetterberg, N.V. Skaane, S. Sæbø, G. Feten, P.D. Rye, L.I. Kristiansen, N. Hagen, M. Jensen, K. Bårdsen, B. Winblad, P. Sharma, A. Lönneborg, A gene expression pattern in blood for the early detection of Alzheimer's disease, J. Alzheimers Dis. 23 (2011) 109-119.

[43] E. Konukoglu, J.P. Coutu, D.H. Salat, B. Fischl, Alzheimer's Disease Neuroimaging Initiative (ADNI), Multivariate statistical analysis of diffusion imaging parameters using partial least squares: application to white matter variations in Alzheimer's disease, Neuroimage 134 (2016) 573-586.

[44] Q. Zhou, M. Goryawala, M. Cabrerizo, W. Barker, D. Loewenstein, R. Duara, M. Adjouadi, Multivariate analysis of structural MRI and PET (FDG and 18F-AV-45) for Alzheimer's disease and its prodromal stages, Conf. Proc. IEEE. Eng. Med. Biol. Soc. 2014 (2014) 1051-1054.

[45] P. Wang, K. Chen, L. Yao, B. Hu, X. Wu, J. Zhang, Q. Ye, X. Guo, Alzheimer's disease neuroimaging initiative. Multimodal classification of mild cognitive impairment based on partial least squares, J. Alzheimers Dis. 54 (2016) 359-371.

[46] M. Toufan, H. Namdar, M. Abbasnezhad, A. Habibzadeh, H. Esmaeili, S. Yaraghi, Z. Samani, Diagnostic values of plasma, fresh and frozen urine NT-proBNP in heart failure patients, J. Cardiovasc. Thorac. Res. 6 (2014) 111-115.

[47] G. Schley, C. Köberle, E. Manuilova, S. Rutz, C. Forster, M. Weyand, I. Formentini, R. Kientsch-Engel, K.U. Eckardt, C. Willam, Comparison of plasma and urine biomarker performance in acute kidney injury, PLoS One 10 (2015) e0145042.

[48] E.R. Peskind, R. Riekse, J.F. Quinn, J. Kaye, C.M. Clark, M.R. Farlow, C. Decarli, C. Chabal, D. Vavrek, M.A. Raskind, D. Galasko, Safety and acceptability of the research lumbar puncture, Alzheimer Dis. Assoc. Disord. 19 (2005) 220-225. 